\title{
science \\ Publication ethics workshop: how to cope with predatory journals
}

\author{
Jong-Ho Park \\ Nuclear Chemistry Research Division, Korea Atomic Energy Research Institute, Daejeon, Korea
}

Date: October 26, 2018

Venue: Content talent campus-Grand conference room, Korea Creative Content Agency, Seoul, Korea

Theme: Predatory journals: current status and countermeasures

Workshop organizer: Korean Council of Science Editors

Since various false academic conferences were reported this year, investigations on the participants and follow-up investigations have been carried out rapidly. Research institutes are also creating a whitelist of academic conferences. In particular, the whitelist includes not only academic conferences but also credible journals, in order to prevent the publication of manuscripts to predatory journals.

As an editorial board member of the Analytical Science \& Technology and the Korean Society for Mass Spectrometry that are striving to become recognized, I had many concerns. Although I encouraged relevant researchers to submit their papers to our journals, thus actively promoting our journals to improve publication rates and diversify our writer pool, I might have accidentally invited misunderstanding and doubt in connection with recent issues surrounding false academic conferences and predatory journals. To avoid such misunderstandings, I had to familiarize myself with predatory journals and their current status. I attended the publication ethics workshop held by the Korean Council of Science Editors under the topic of "Predatory journals: current trends and countermeasures" to help address these issues (Fig. 1). On the day of the workshop, it was raining somewhat heavily, but people attended, despite the inclement weather, and filled the lecture hall.

Fake academic journals are generally called "predatory journals." These journals have an unqualified, fraudulent editorial staff and publish manuscripts without any proper review pro-

Received: January 24, 2019 Accepted: January 31, 2019

Correspondence to Jong-Ho Park jongho@kaeri.re.kr

ORCID

Jong-Ho Park

https://orcid.org/0000-0001-7371-4555 cesses. Predatory journals only exist to receive article processing charge rather than for sharing academic and technological achievements, as most academic journals do, so they do not hold any value as legitimate academic journals. In principle, academic journals without academic value die out, but the deceptive commercial purposes of these false academic journals satisfy the interests of some dishonest researchers, in that they easily address the pressure from research achievements, thereby prolonging the existence of these fake academic journals.

The first presentation "Current trends and countermeasures" and the second "Current status/ 


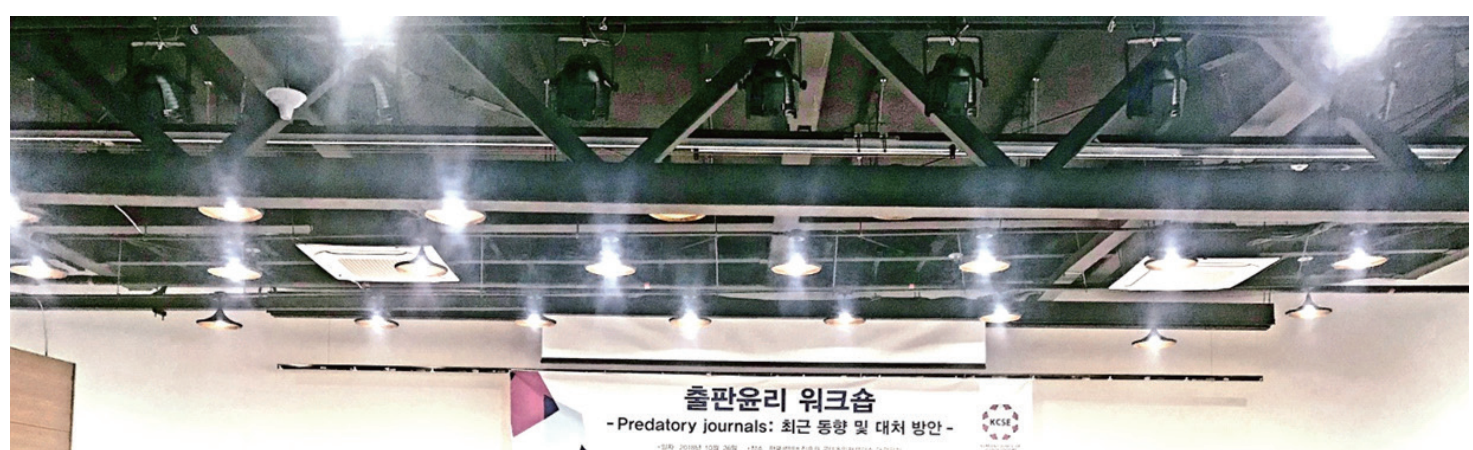

$\Delta$

datory journals: 최근 동향 및 대처 방안

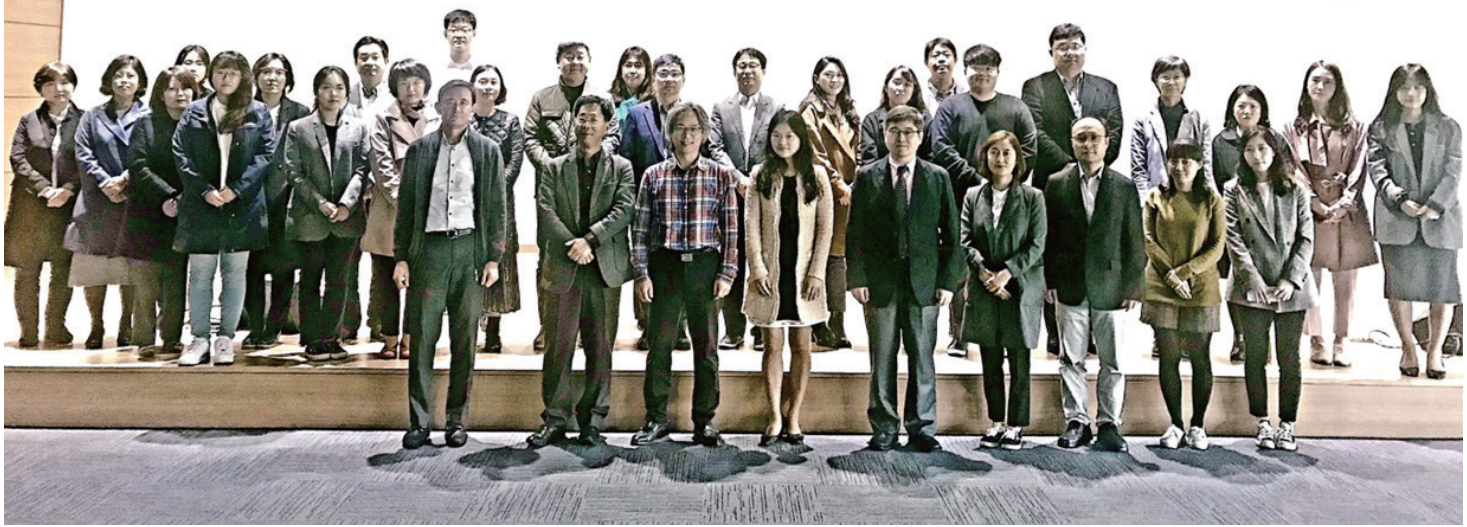

Fig. 1. Group photo from the Publication Ethics Workshop.

cases/countermeasures" included explanations and discussion about the current status of predatory journals. Predatory journals are exploiting the recent development of open access (OA) journals. OA journals, which grant public access to research, often require article processing charge from manuscript writers to maintain the journals. Predatory journals attempt to justify their fees in a similar way to these OA journals.

According to a 2015 report, there were about 8,000 predatory journals in 2014, and about 410,000 articles were published in these journals. I was surprised to learn that the number of predatory journals listed in Scopus or SCI is continuously increasing. Eventually, researchers may grow to trust an academic journal listed in the internationally recognized citation index and unintentionally submit their manuscript to a predatory journal. This means that it is not always easy to distinguish between predatory journals and relatively unknown international journals with proper academic values, like many domestic journals. Thus, international citation databases are reinforcing the examination of listed academic journals and are deleting journals that have been caught. In addition, they are reassessing research ethics and management regulations nationwide and striving to monitor predatory journals. However, the research ethics of researchers who resist the temptation of fast and easy research achievements and who share their research results through proper channels and the aca- demic world's efforts to reform itself are most important.

The third presentation was titled, "The survey results of the researchers' recognition about false conference World Academy of Science, Engineering and Technology (WASET) and countermeasure," which summarized survey results for 13 items using data from 1,100 researchers from universities, national organizations, research institutes, and companies in Republic of Korea in 2018. Although this survey investigated false academic conferences rather than predatory journals, I was interested in the results because I thought that they could provide insight on the current status of predatory journals. According to this report, a majority of respondents answered that the problems with the quantitative research project evaluation index were the main reasons for the recent issue of false academic conferences, and only $33 \%$ of respondents said that this issue resulted from academic dishonesty of individual researchers. This suggests that as long as research project evaluations are highly dependent on the number of academic achievements, researchers will constantly be exposed to the temptation of false academic conferences and predatory journals. I found the opinion that hasty punishment in response to critical public opinion or the addition of regulations may violate the autonomy and efficiency of the research field highly persuasive.

The fourth presentation was "Problems on academic communication.” Predatory journals only pursue a commercial 


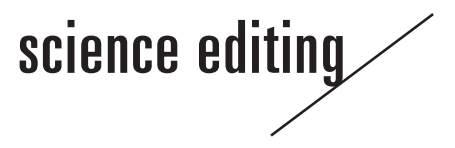

goal, so they publish articles without any qualitative examination to maximize their profits. Therefore, I believe that transparent peer review is the key to preventing the prevalence of predatory journals. This is in line with open science, a system that is transparently validated by disclosing research results to more researchers. Various platforms for implementing open science have been established and utilized. The emergence of predatory journals is not the only reason the open science system is necessary; the open science system will significantly assist in addressing the negative effects of predatory journals. In conclusion, academic journals will develop in parallel with open science along with introduction of digital publication, open access, and various identifiers.

After the workshop ended, I thought about why I attended this workshop. As an editorial board member, what can I do to differentiate our journal from other journals so that it is not confused for a predatory journal? We had only made efforts to list our journal in international citation indices, such as Scopus and SCI, and believed that the qualitative and ethical issues of journals would automatically be solved if our journal was listed; however, the negative effects of predatory journals have shown that this is not the case. In the end, only by bolstering an expert review system that strictly and transparently evaluates papers submitted to journals can the intrinsic value of academic journals be recognized. I will consider this fact to be a starting point and contemplate what editors and editorial board members should do to establish such a system.

I think that all researchers, as well as editors, should be interested in this workshop, because every researcher needs to take a healthy and progressive approach to presenting their research. Although we should support institutional efforts to improve the environment that results in researchers being attracted by predatory journals, researchers are responsible for producing sound research based on integrity. To do so, we should reassess our research ethics and reject dishonest shortcuts.

\section{Conflict of Interest}

No potential conflict of interest relevant to this article was reported. 